\title{
Fungal Infections Caused by Kazachstania spp., Strasbourg, France, 2007-2020
}

\author{
Charlotte Kaeuffer, Mathieu Baldacini, Tiffany Ruge, Yvon Ruch, Yves-Jean Zhu, Manon De Cian, \\ Guillaume Philouze, Philippe Bachellier, Julie Denis, Nicolas Lefebvre, Francis Schneider, \\ Yves Hansmann, Valérie Letscher-Bru, Raoul Herbrecht, Marcela Sabou, François Danion
}

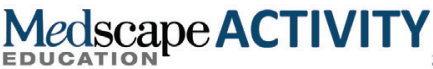

In support of improving patient care, this activity has been planned and implemented by Medscape, LLC and Emerging Infectious Diseases. Medscape, LLC is jointly accredited by the Accreditation Council for Continuing Medical Education (ACCME), the Accreditation Council for Pharmacy Education (ACPE), and the American Nurses Credentialing Center (ANCC), to provide continuing education for the healthcare team.

Medscape, LLC designates this Journal-based CME activity for a maximum of 1.00 AMA PRA Category 1 Credit(s) ${ }^{\mathrm{TM}}$. Physicians should claim only the credit commensurate with the extent of their participation in the activity.

Successful completion of this CME activity, which includes participation in the evaluation component, enables the participant to earn up to $1.0 \mathrm{MOC}$ points in the American Board of Internal Medicine's (ABIM) Maintenance of Certification (MOC) program. Participants will earn MOC points equivalent to the amount of CME credits claimed for the activity. It is the CME activity provider's responsibility to submit participant completion information to ACCME for the purpose of granting ABIM MOC credit.

All other clinicians completing this activity will be issued a certificate of participation. To participate in this journal CME activity: (1) review the learning objectives and author disclosures; (2) study the education content; (3) take the post-test with a $75 \%$ minimum passing score and complete the evaluation at http://www.medscape.org/journal/eid; and (4) view/print certificate. For CME questions, see page 273.

Release date: December 17, 2021; Expiration date: December 17, 2022

Learning Objectives

Upon completion of this activity, participants will be able to:

- Distinguish mammals that can be infected with Kazachstania bovina

- Assess clinical characteristics of persons with positive testing for Kazachstania spp.

- Analyze the antifungal resistance pattern of Kazachstania spp.

- Evaluate potential risk factors for a positive test for Kazachstania spp.

CME Editor

P. Lynne Stockton Taylor, VMD, MS, ELS(D), Technical Writer/Editor, Emerging Infectious Diseases. Disclosure: P. Lynne Stockton Taylor, VMD, MS, ELS(D), has disclosed no relevant financial relationships.

\section{CME Author}

Charles P. Vega, MD, Health Sciences Clinical Professor of Family Medicine, University of California, Irvine School of Medicine, Irvine, California. Disclosure: Charles P. Vega, MD, has disclosed the following relevant financial relationships: served as an advisor or consultant for Johnson \& Johnson.

\section{Authors}

Disclosures: Charlotte Kaeuffer, MD; Mathieu Baldacini, MD; Tiffany Ruge, MD; Yvon Ruch, MD; Yves-Jean Zhu, BS; Manon De Cian, MD; Guillaume Philouze, MD; Philippe Bachellier, MD; Julie Denis, PharmD; Nicolas Lefebvre, MD; Francis Schneider, MD, PhD; Yves Hansmann, MD; Valérie Letscher-Bru, PhD; and Marcela Sabou, MD, PhD, have disclosed no relevant financial relationships. Raoul Herbrecht, MD, has disclosed the following relevant financial relationships: served as an advisor or consultant for Astellas Pharma, Inc.; Basilea Pharmaceutica Ltd.; Gilead Sciences, Inc.; Merck Sharp \& Dohme GmbH; Pfizer Inc.; served as a speaker or a member of a speakers bureau for Amgen Inc.; Gilead Sciences, Inc.; Pfizer Inc.; received grants for clinical research from Gilead Sciences, Inc.; Novartis Pharmaceuticals Corporation. François Danion, MD, PhD, has disclosed the following relevant financial relationships: served as a speaker or a member of a speakers bureau for Gilead Sciences, Inc.

Author affiliations: Hôpitaux Universitaires de Strasbourg, Strasbourg, France (C. Kaeuffer, M. Baldacini, T. Ruge, Y. Ruch, Y.-J. Zhu, M. De Cian, G. Philouze, P. Bachellier, J. Denis, N. Lefebvre, F. Schneider, Y. Hansmann, V. Letscher-Bru, R. Herbrecht, M. Sabou, F. Danion); Institut de Cancérologie Strasbourg Europe, Strasbourg (R. Herbrecht); INSERM UMR-S1109, Strasbourg (F. Danion)

DOI: https://doi.org/10.3201/eid2801.211543 
Rare fungal pathogens are emerging as agents of invasive fungal infections. We analyzed 13 cases of fungal infections caused by Kazachstania (Arxiozyma) spp. in Strasbourg University Hospital, Strasbourg, France. Among the cases, 4 patients had proven fungal disease ( 3 cases of invasive fungal disease and 1 mucocutaneous infection) and 9 were colonized by Kazachstania (Arxiozyma) spp. Candida albicans was also isolated from 11 of the 13 patients. None of the patients with proven invasive fungal disease met host criteria, but most had underlying diseases. All strains were identified as $K$. telluris by matrix-assisted laser desorption/ ionization time-of-flight mass spectrometry, and 3 were confirmed as $K$. bovina by internal transcribed spacer sequencing. For all tested strains, the MICs for fluconazole were $\geq 2 \mu \mathrm{g} / \mathrm{mL}$. Emergence of this rare fungal infection might be explained by the increasing number of patients with immunocompromised conditions and gastroesophageal diseases.

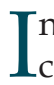
ncidence of invasive fungal infections (IFI) has increased over the past 2 decades, mostly associated with candidemia (1). Rare fungal pathogens have also emerged as agents causing IFI, notably in immunocompromised persons (2).

Kazachstania (Arxiozyma) spp. are ubiquitous yeasts belonging to the Saccharomycetaceae family. Kazachstania bovina was described as Saccharomyces tellustris in 1957, as Candida bovina in 1958, as Torulopsis bovina in 1970, and finally as K. bovina in 2005 on the basis of multigene phylogenetic analyses (3-5). K. bovina belongs to the $K$. telluris species complex, which also includes K. pintolopesii, K. sloofiae, K. heterogenica, and K. telluris (5). Recently, a case of IFI caused by C. bovina (the former name of $K$. bovina in humans) was described (6). We report a case series of fungal infections caused by Kazachstania (Arxiozyma) spp. and classify them as invasive infections, mucocutaneous infections, or colonizations. We also describe the antifungal susceptibility testing and the methods used to identify the species.

This analysis is part of a study of opportunistic infections approved by the institutional ethics committee of the Hôpitaux Universitatires de Strasbourg. According to regulations in France, the database was declared to the Commission Nationale de l'Informatique et des Libertés. The study was registered at ClinicalTrials.gov (no. NCT03920735).

\section{Methods}

To conduct a retrospective observational study of Kazachstania spp. infections, we identified all patients in the Strasbourg University Hospital, a 2000bed tertiary-care hospital, who had Kazachstania
(Arxiozyma) spp.-positive samples during 2007-2020. We collected data on demographics, underlying diseases, clinical and radiologic aspects, mycologic results, treatments, and outcomes.

We classified Kazachstania spp. diseases as proven IFI according to the European Organization for Research and Treatment of Cancer and the Mycoses Study Group Education and Research Consortium updated consensus or as mucocutaneous infections (7). We defined colonization as isolation of Kazachstania spp. from a nonsterile site and absence of associated clinical and radiologic signs.

We incubated blood cultures by using Bactec Mycosis IC/F Plus Aerobic/F media (Becton Dickinson, https://www.bd.com) at $37^{\circ} \mathrm{C}$. Other samples were incubated at $35^{\circ} \mathrm{C}$ on Sabouraud chloramphenicol agar or on chromogenic media chromID Candida (bioMérieux, https://www.biomerieux.fr) before December 2019 and CHROMagar Candida (Becton Dickinson) thereafter. We used a slide culture on potato carrot bile medium (Bio-Rad Laboratories, https://www.bio-rad.com) to microscopically observe K. bovina.

We identified the strains by using matrix-assisted laser desorption/ionization time-of-flight (MALDITOF) mass spectrometry on a Microflex spectrometer and using BioTyper software (Brüker Daltonics, https://www.bruker.com). We confirmed species identification by sequencing the internal transcribed spacer (ITS) region of the ribosomal DNA with primers ITS1 and ITS4 (Eurofins Genomics GmbH, https://eurofinsgenomics.eu) (8). We compared sequences with those in GenBank by BLAST analysis (https://blast.ncbi.nlm.nih.gov/Blast.cgi) and with those in the Westerdijk Fungal Biodiversity Institute database (https://www.wi.knaw.nl). We performed antifungal susceptibility testing by using Etest or ATB Fungus 3 methods (bioMérieux). The French National Reference Center for Mycoses and Antifungals tested 1 isolate by using the microdilution method according to the European Committee on Antimicrobial Susceptibility Testing (EUCAST) guidelines (https:/ / eucast.org) (RESSIF no. 20319).

\section{Results}

We identified 13 patients with Kazachstania (Arxiozyma) spp.- positive samples. We found no temporal or spatial hospital associations between cases. Median patient age was 63 (range 40-77) years, and 7 (53.8\%) patients were male (Table 1). Of the 13 patients, 4 had a proven fungal disease, of which 3 were classified as IFI: 1 case of fungemia and pyelonephritis, 1 mediastinitis (Figure 1), and 1 angiocholitis. The 
Table 1. Clinical characteristics of Kazachstania spp. infections and colonizations, Strasbourg, France, 2007-2020*

\begin{tabular}{|c|c|c|c|c|c|c|}
\hline Patient & Age, $y /$ sex & Underlying condition & Exposure & Type of infection & Therapy & Outcome \\
\hline 1 & $67 / F$ & $\begin{array}{l}\text { Diabetes, endometrial cancer } \\
\text { (remission) }\end{array}$ & Pigeon & Fungemia + UTI & FLC + CAS & Survived \\
\hline 2 & $63 / F$ & Esophagus squamous cell carcinoma & Pigeon & $\begin{array}{l}\text { Mediastinitis after } \\
\text { gastric ulceration }\end{array}$ & CAS & Survived \\
\hline 3 & $66 / \mathrm{M}$ & $\begin{array}{c}\text { CDP (endocrine carcinoma), recurrent } \\
\text { angiocholitis }\end{array}$ & NA & Angiocholitis & $\begin{array}{c}\text { FLC, } \\
\text { surgery† }\end{array}$ & Survived \\
\hline 4 & $84 / F$ & Esophageal achalasia & None & Esophagitis & $\begin{array}{c}\text { PPI, } \\
\text { surgery } \ddagger\end{array}$ & Survived \\
\hline 5 & $68 / F$ & $\begin{array}{c}\text { CVID, gastro-jejunal anastomotic } \\
\text { stenosis }\end{array}$ & NA & Colonization & None & Survived \\
\hline 6 & 46/M & $\begin{array}{l}\text { Caustic esophageal stenosis, } \\
\text { pneumonia }\end{array}$ & NA & Colonization & None & Survived \\
\hline 7 & $59 / F$ & Systemic scleroderma & NA & Colonization & None & $\begin{array}{l}\text { Died (cardiogenic } \\
\text { shock) }\end{array}$ \\
\hline 8 & 40/M & $\begin{array}{l}\text { Former smoker, Staphylococcus } \\
\text { ventilator-associated pneumonia }\end{array}$ & NA & Colonization & None & Survived \\
\hline 9 & $51 / \mathrm{F}$ & AutoHSCT for oculo-cerebral NHL & NA & Colonization & FLC & Survived \\
\hline 10 & $60 / \mathrm{M}$ & $\begin{array}{l}\text { Proven Mycobacterium fortuitum } \\
\text { infection }\end{array}$ & NA & Colonization & None & Survived \\
\hline 11 & $59 / \mathrm{M}$ & COPD, emphysema, denutrition & NA & Colonization & None & Survived \\
\hline 12 & $77 / \mathrm{M}$ & $\begin{array}{l}\text { Congestive heart failure, ischemic } \\
\text { cardiomyopathy, smoker }\end{array}$ & NA & Colonization & None & $\begin{array}{l}\text { Died; multiorgan } \\
\text { failure after cardiac } \\
\text { surgery }\end{array}$ \\
\hline 13 & $66 / M$ & $\begin{array}{l}\text { Angioimmunoblastic T-cell lymphoma, } \\
\text { neutropenia, pulmonary tuberculosis }\end{array}$ & NA & Colonization & None & $\begin{array}{c}\text { Died } 5 \text { mo later; } \\
\text { cerebral } \\
\text { toxoplasmosis, T-cell } \\
\text { lymphoma } \\
\text { progression } \\
\end{array}$ \\
\hline \multicolumn{7}{|c|}{$\begin{array}{l}\text { *AutoHSCT, autologous hematopoietic stem cell transplantation; CDP, cephalic duodenopancreatectomy; CAS, caspofungin; COPD, chronic obstructive } \\
\text { pulmonary disease; CVID, common variable immunodeficiency; FLC, fluconazole; NHL, non-Hodgkin lymphoma; NA, not applicable; PPI, proton pump } \\
\text { inhibitor; UTI, urinary tract infection. } \\
\text { †Degastrogastrectomy and hepatico-jejunal and gastrointestinal anastomosis. } \\
\text { †Peroral endoscopic myotomy to treat achalasia. }\end{array}$} \\
\hline
\end{tabular}

fourth patient had a mucocutaneous infection with biopsy-proven esophageal infection. Presence of $\mathrm{Ka}$ zachstania spp. in the other 9 patients was classified as colonization. Most patients had underlying diseases that might have favored the infection or colonization, but none of the patients with proven IFI met the European Organisation for Research and Treatment of Cancer/Mycoses Study Group Education and Research Consortium host criteria (7). Of note, underlying esophageal pathology was reported for 4 of the 13 patients. Among the 4 patients with proven infections, treatment was caspofungin for 2 and surgery for the other 2 (in addition to proton pump inhibitor for 1 patient with esophageal infection) without any effective antifungal treatment against Kazachstania spp. The outcome was favorable for all 4 patients with proven infection.

The colonies appeared white on Sabouraud chloramphenicol agar and the chromID Candida medium and pink on the CHROMagar Candida medium. Growth was slower on the chromID Candida medium than on the other 2 media (Figure 2). A slide culture of $\mathrm{K}$. bovina incubated for $72 \mathrm{~h}$ at $27^{\circ} \mathrm{C}$ on potato carrot bile medium showed spherical to ellipsoidal yeast cells with multilateral budding, without filamentation. Some asci containing ascospores were visible.

MALDI-TOF mass spectrometry identified all strains in this study as K. telluris (Table 2). Because mass spectrometry cannot distinguish between the species of the K. telluris complex, we identified the strains involved in IFIs, and therefore stored in our laboratory, by ITS sequencing and confirmed them as K. bovina (GenBank accession nos. MZ435268, MZ435269, and MZ435270). The sequences from the strains in this study were $100 \%$ similar to 2 other $K$. bovina isolates from 2 different centers (GenBank accession nos. KY103626.1 and NR_144228.1).

For all strains tested, MICs for fluconazole were $2 \mu \mathrm{g} / \mathrm{mL}$ to $>256 \mu \mathrm{g} / \mathrm{mL}$ (Table 2). For 11 of the 13 patients, including all with proven fungal infection, we identified another Candida species (most often $C$. albicans) (Table 2).

Two patients with invasive infection reported exposure to pigeons. Moreover, culture of a sample of pigeon droppings from the aviary of patient 1 enabled identification of $K$. bovina by ITS sequencing (GenBank accession no. OK037112). 

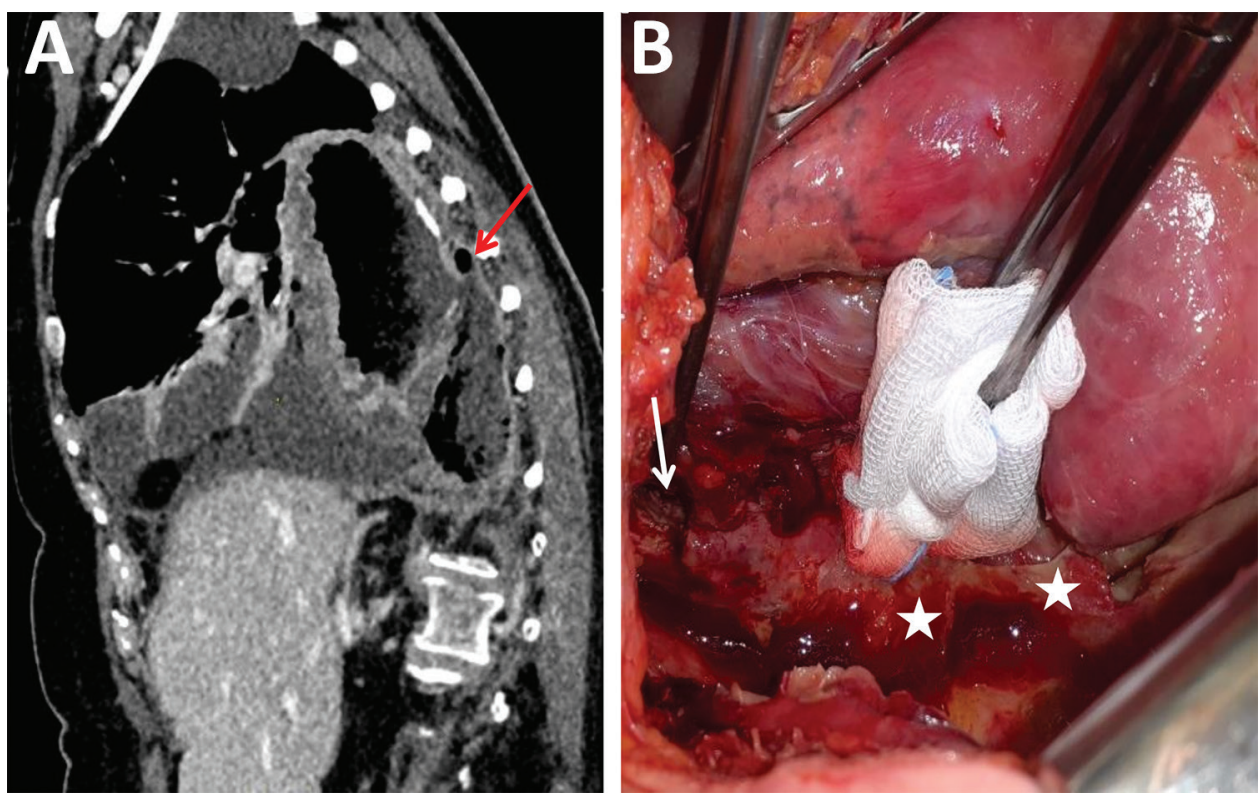

Figure 1. Clinical and radiologic characteristics of mediastinitis caused by Kazachstania bovina (patient 2), Strasbourg, France. A) Computed tomography image demonstrating stomach ulceration (arrow), mediastinitis, and pleuritis. B) Photograph taken after right-side thoracotomy, showing posterior stomach ulceration (arrow) and false membranes (stars). Culture of biopsy samples grew K. bovina, Candida albicans, $C$. glabrata, and bacteria.

\section{Discussion}

Among the K. telluris species complex, host specificity for $K$. bovina seems to be low because it has been isolated only from pigeons, a cow, and humans $(4,5)$. To date, only 2 cases of invasive human infection caused by K. telluris complex have been described $(6,9)$. One case was a $K$. bovina bloodstream infection, and the other was mediastinis caused by K. slooffiae. An article about extremely rare invasive fungal infections collected in the FungiScope registry did not include any cases of Kazachstania infection (10).

The isolation of $K$. bovina from 2 blood cultures from patient 1 in this study, as well as from a patient by Brunet et al. (6), clearly suggests pathogenicity of this fungus. Nevertheless, we identified another Candida species (most often C. albicans) in 11 of the 13 patients in our study, including all with proven fungal infection.

Most patients had an underlying condition that might have favored the infection, including a gastroesophageal pathologic condition in 4 of the 13 patients in our study, similar to the cases reported by Brunet et al. and Mercier et al., suggesting a possible portal of entry $(6,9)$. Moreover, 2 patients with IFI in our study reported exposure to pigeons; for 1 patient, we also isolated $K$. bovina from the pigeon droppings. Even if $K$. telluris complex in pigeons had been previously identified, to our knowledge, no cases of zoonotic transmission have been reported (5).

MALDI-TOF mass spectrometry identification of all strains as $K$. telluris, and further identification of 3 strains involved in IFI by ITS sequencing as K. bovina show the value of sequencing emerging pathogens for proper identification and epidemiology. Misidentification or incomplete identification has been noticed in a previous report of human infection with K. bovina (6).

No specific breakpoints have been established for the antifungal susceptibility of Kazachstania spp.

Figure 2. Macroscopic and microscopic examinations of Kazachstania bovina from a patient in Strasbourg, France. A) Macroscopic aspect of $K$. bovina on 3 agar media: Sabouraud (top), CHROMID Candida (bioMérieux, https:// www.biomerieux.fr) (lower left), and CHROMagar Candida (Becton Dickinson, https://www. bd.com) (lower right). B) $K$. bovina slide-culture on potato carrot bile agar (incubation

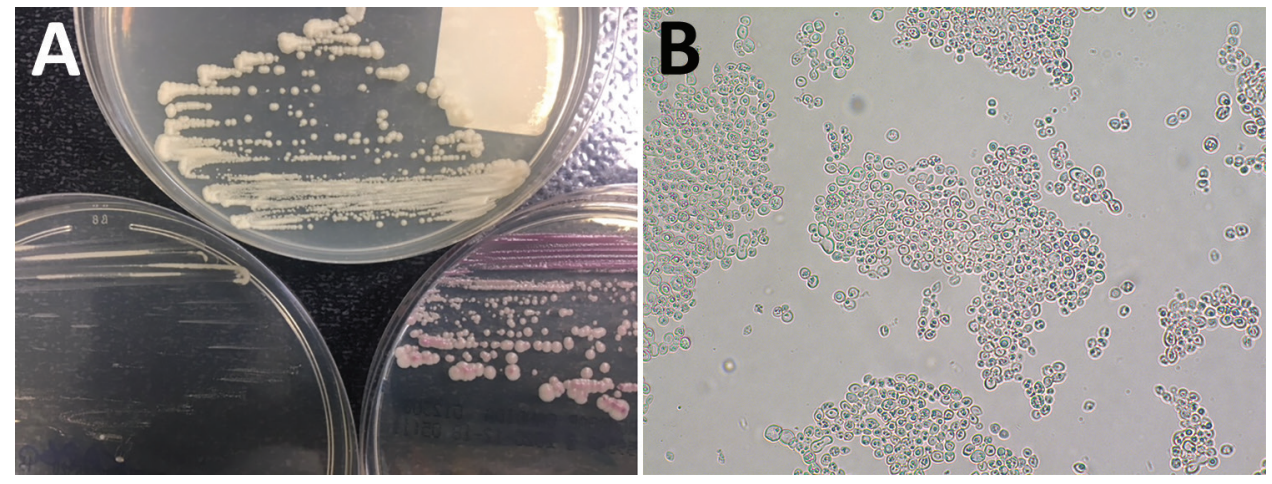
for $72 \mathrm{~h}$ at $27^{\circ} \mathrm{C}$, original magnification $\times 400$ ), showing spherical to ellipsoidal yeast cells with multilateral budding, without filamentation, and some asci containing ascospores. 
Table 2. Mycologic characteristics of Kazachstania spp. infections and colonizations, Strasbourg, France, 2007-2020*

\begin{tabular}{|c|c|c|c|c|c|c|c|c|c|c|}
\hline \multirow[b]{2}{*}{ Patient } & \multirow[b]{2}{*}{ Sample } & \multirow[b]{2}{*}{ Fungus species } & \multirow{2}{*}{$\begin{array}{c}\text { Identification } \\
\text { technique }\end{array}$} & \multicolumn{6}{|c|}{ Antifungal susceptibility, $\mu \mathrm{g} / \mathrm{mL}$} & \multirow{2}{*}{$\begin{array}{c}\text { GenBank } \\
\text { accession no. }\end{array}$} \\
\hline & & & & Method & FLC & VRC & $5 \mathrm{FC}$ & AMB & CAS & \\
\hline \multirow[t]{2}{*}{1} & 2 blood cultures, & K. bovina & Sequencing & Etest & 24 & 0.125 & 0.012 & 0.047 & 0.25 & MZ435268 \\
\hline & & & & EUCAST & 2 & $<0.016$ & $<0.125$ & 0.015 & 0.015 & \\
\hline 2 & $\begin{array}{l}\text { Mediastinal } \\
\text { collection; false } \\
\text { membranes; } \\
\text { pleural fluid } †\end{array}$ & $\begin{aligned} & \text { K. bovina } \\
+ & \text { C. albicans, } \\
+ & \text { C. glabrata }\end{aligned}$ & Sequencing & Etest & 8 & 0.125 & NA & 0.5 & 0.19 & MZ435270 \\
\hline 3 & $\begin{array}{l}\text { Bile (surgical } \\
\text { sample) }\end{array}$ & $\begin{array}{l}\text { K. telluris SC } \\
+ \text { C. albicans }\end{array}$ & MALDI-TOF & Etest & $>256$ & 0.19 & NA & 0.047 & 0.25 & Not stored \\
\hline 4 & $\begin{array}{l}\text { Esophageal } \\
\text { biopsy; } \\
\text { fibroscopy: white } \\
\text { plaques of the } \\
\text { mucosa }\end{array}$ & $\begin{aligned} & \text { K. bovina } \\
+ & \text { C. albicans }\end{aligned}$ & Sequencing & Etest & 6 & 0.032 & NA & 0.125 & 0.25 & MZ435269 \\
\hline 5 & Gastric liquid & $\begin{array}{l}\text { K. telluris SC } \\
+ \text { C. albicans }\end{array}$ & MALDI-TOF & & NA & NA & NA & NA & NA & Not stored \\
\hline 6 & BAL fluid & K. telluris SC & MALDI-TOF & & NA & NA & NA & NA & NA & Not stored \\
\hline 7 & Stool & $\begin{array}{l}\text { K. telluris SC } \\
+ \text { C. Iusitaniae }\end{array}$ & MALDI-TOF & & NA & NA & NA & NA & NA & Not stored \\
\hline 8 & BAL fluid & K. telluris SC & MALDI-TOF & & NA & NA & NA & NA & NA & Not stored \\
\hline 9 & Urine, stool & $\begin{array}{l}\text { K. telluris SC } \\
+ \text { C. albicans }\end{array}$ & MALDI-TOF & & NA & NA & NA & NA & NA & Not stored \\
\hline 10 & BAL fluid & $\begin{array}{l}\text { K. telluris SC } \\
+ \text { C. albicans }\end{array}$ & MALDI-TOF & & NA & NA & NA & NA & NA & Not stored \\
\hline 11 & Sputum & $\begin{array}{l}\text { K. telluris SC } \\
+ \text { C. albicans } \\
\text { C. dubliniensis } \\
\text { A. niger }\end{array}$ & MALDI-TOF & $\begin{array}{l}\text { AMB- } \\
\text { fungus }\end{array}$ & 4 & 0.25 & $<4$ & $<0.5$ & NA & Not stored \\
\hline 12 & Stool & $\begin{array}{l}\text { K. telluris SC } \\
+ \text { C. albicans }\end{array}$ & MALDI-TOF & & NA & NA & NA & NA & NA & Not stored \\
\hline 13 & BAL fluid, stool & $\begin{array}{l}\text { K. telluris } \\
+ \text { C. kefyr }\end{array}$ & MALDI-TOF & $\begin{array}{l}\text { AMB- } \\
\text { fungus }\end{array}$ & 8 & 0.125 & $<4$ & $<0.5$ & NA & Not stored \\
\hline $\begin{array}{l}\text { *AMB, a } \\
\text { Committ } \\
\text { desorptic } \\
\text { †Anatom } \\
\ddagger \text { Anatom }\end{array}$ & $\begin{array}{l}\text { lotericin B; AMB; B } \\
\text { on Antimicrobial Su } \\
\text { onization time-of-fli } \\
\text { athologic examinati } \\
\text { athologic examinati }\end{array}$ & $\begin{array}{l}\text { oronchoalveola } \\
\text { tibility Testing; } \\
\text { lass spectrome } \\
\text { f the gastric per } \\
\text { f the esophage }\end{array}$ & $\begin{array}{l}\text { e; CAS, cas } \\
\text { flucytosine; } F \\
\text { A, not applice } \\
\text { on showed ne } \\
\text { sy showed } n\end{array}$ & $\begin{array}{l}\text { yin; Etest } \\
\text { uconazol } \\
\text { C, speci } \\
\text { and infl } \\
\text { s of inva }\end{array}$ & atic & $\begin{array}{l}\text {, https: } \\
\text { nazole } \\
\text { VRC, }\end{array}$ & $\begin{array}{l}\text { W.bio } \\
\text { LDI- } \\
\text { onazc }\end{array}$ & $\begin{array}{l}\text { ux.fr) } \\
\text { natrix }\end{array}$ & $\begin{array}{l}\text { CAST, } \\
\text { sisted li }\end{array}$ & opean \\
\hline
\end{tabular}

EUCAST non-species-related breakpoints for Candida are $\leq 2 \mu \mathrm{g} / \mathrm{mL}$ (susceptible) and $>4 \mu \mathrm{g} / \mathrm{mL}$ (resistant). Our finding of fluconazole MICs between $2 \mu \mathrm{g} / \mathrm{mL}$ and $>256 \mu \mathrm{g} / \mathrm{mL}$ for tested strains in our study suggests decreased susceptibility to this molecule in 5 of 7 isolates. MICs for the other antifungals tested were low for all strains. Our MIC results should be considered with caution because for 1 isolate, Etest and EUCAST indicated different fluconazole MICs. The antifungal susceptibility testing performed by the National Reference Center on Invasive Mycoses and Antifungals, using the EUCAST method on 31 strains of Kazachstania spp., showed high azole MICs for 55\% of isolates and high caspofungin MICs for $6.5 \%$ (11). More recent testing of 5 $K$. bovina isolates showed fluconazole MICs to range from 2 to $8 \mu \mathrm{g} / \mathrm{mL}$ (12). To determine the susceptibility of Kazachstania spp. to fluconazole, the EUCAST microdilution method should be used to determine MICs for more isolates.
No specific antigens have been designed for the diagnosis of Kazachstania infections. We would like to have assessed the $(1 \rightarrow 3)-\beta$-D-glucan (Fungitell, https://www.fungitell.com) panfungal antigen in the serum of the patients in our study, but this test was not available in our laboratory before 2020. However, because we identified another species of Candida in 11 of the 13 patients in our study, the contribution of the $(1 \rightarrow 3)-\beta$-D-glucan test might be debatable.

The retrospective design of our study led to some limitations. We retrospectively classified cases of invasive infection or colonization, but we might have missed some information (7). Sequencing and antifungal susceptibility testing were not performed on all strains, notably those that were not involved in invasive fungal infections and were not stored.

The emergence of this very rare fungal infection might be explained by the increasing number of 
patients with immunocompromised conditions and gastroesophageal diseases. The use of MALDI-TOF mass spectrometry and ITS sequencing to identify yeasts might also contribute to increased documentation of these fungal infections.

\section{Acknowledgments}

We thank Marie Desnos-Ollivier and Yannis Mesli.

\section{About the Author}

Dr. Kaeuffer is a medical doctor who works in infectious diseases in the University Hospital of Strasbourg, France, with a special interest in medical mycology.

\section{References}

1. Bitar D, Lortholary O, Le Strat Y, Nicolau J, Coignard B, Tattevin $\mathrm{P}$, et al. Population-based analysis of invasive fungal infections, France, 2001-2010. Emerg Infect Dis. 2014;20:1149-55. https://doi.org/10.3201/eid2007.140087

2. Arendrup MC, Boekhout T, Akova M, Meis JF, Cornely OA, Lortholary O; European Society of Clinical Microbiology and Infectious Diseases Fungal Infection Study Group; European Confederation of Medical Mycology. ESCMID and ECMM joint clinical guidelines for the diagnosis and management of rare invasive yeast infections. Clin Microbiol Infect. 2014;20(Suppl 3):76-98. https:/ / doi.org/10.1111/ 1469-0691.12360

3. Van Der Walt JP. Three new sporogenous yeasts from soil. Antonie van Leeuwenhoek. 1957;23:23-9. https://doi.org/ 10.1007/BF02545856

4. Kreger-Van Rij NJ. The relationship between Saccharomyces tellustris and Candida bovina. Antonie van Leeuwenhoek. 1958;24:137-44. https:// doi.org/10.1007/BF02548441

5. Kurtzman CP, Robnett CJ, Ward JM, Brayton C, Gorelick P, Walsh TJ. Multigene phylogenetic analysis of pathogenic Candida species in the Kazachstania (Arxiozyma) telluris complex and description of their ascosporic states as Kazachstania bovina sp. nov., K. heterogenica sp. nov., K. pintolopesii sp. nov., and K. slooffiae sp. nov. J Clin
Microbiol. 2005;43:101-11. https://doi.org/10.1128/ JCM.43.1. 101-111.2005

6. Brunet K, Minoza A, Rammaert B, Portet-Sulla V, Hubert F, Lorenzo J-C, et al. Invasive Candida bovina infection, France. Emerg Infect Dis. 2020;26:626-7. https:// doi.org/10.3201/ eid2603.191371

7. Donnelly JP, Chen SC, Kauffman CA, Steinbach WJ, Baddley JW, Verweij PE, et al. Revision and update of the consensus definitions of invasive fungal disease from the European Organization for Research and Treatment of Cancer and the Mycoses Study Group Education and Research Consortium. Clin Infect Dis. 2020;71:1367-76.

8. Irinyi L, Serena C, Garcia-Hermoso D, Arabatzis M, Desnos-Ollivier M, Vu D, et al. International Society of Human and Animal Mycology (ISHAM)-ITS reference DNA barcoding database - the quality controlled standard tool for routine identification of human and animal pathogenic fungi. Med Mycol. 2015;53:313-37. https://doi.org/10.1093/ mmy/myv008

9. Mercier V, Desnos-Ollivier M, Lamy A, Mahul M, Sasso M. Kazachstania slooffiae: an unexpected journey to a human pleural sample. J Mycol Med. 2021;31:101109. https:/ / doi.org/10.1016/j.mycmed.2020.101109

10. Salmanton-García J, Koehler P, Kindo A, Falces-Romero I, García-Rodríguez J, Ráčil Z, et al.; ECMM/ISHAM working group. Needles in a haystack: extremely rare invasive fungal infections reported in FungiScope-Global Registry for Emerging Fungal Infections. J Infect. 2020;81: 802-15. https://doi.org/10.1016/j.jinf.2020.08.015

11. Desnos-Ollivier M, Robert V, Raoux-Barbot D, Groenewald M, Dromer F. Antifungal susceptibility profiles of 1698 yeast reference strains revealing potential emerging human pathogens. PLoS One. 2012;7:e32278. https://doi.org/10.1371/journal.pone.0032278

12. Desnos-Ollivier M, Lortholary O, Bretagne S, Dromer F. Azole susceptibility profiles of more than 9,000 clinical yeast isolates belonging to 40 common and rare species. Antimicrob Agents Chemother. 2021;65:e02615-20. https://doi.org/10.1128/AAC.02615-20

Address for correspondence: François Danion, Department of Infectious and Tropical Diseases, 1 Place de l'Hôpital, 67000

Strasbourg, France; email: francois.danion@chru-strasbourg.fr 